\title{
A new type of compact precision amplifier for strain gauge based transducers
}

\author{
André Schäfer \\ Hottinger Balwin Messtechnik GmbH (HBM), Im Tiefen See 45, 64293 Darmstadt, Germany
}

\begin{abstract}
Resumé: TITRE en français: "Un nouveau type d'amplificateur de précision compact pour des capteurs à jauge de contrainte" : Si la précision est importante, des grandeurs mécaniques telles que la force, le couple ou la pression sont presque exclusivement réalisées par des capteurs à jauges de contrainte. Pour exploiter le potentiel des mesures statiques, les exigences sur les amplificateurs de haute précision augmentent régulièrement. Contrairement aux capteurs, l'amélioration de la précision des amplificateurs peut aller très loin tandis que leur design est toujours plus compact. Le nouvel amplificateur se distingue par ses deux canaux indépendants (qui mesurent simultanément), chacun offrant une classe de précision de 0,0025 (25 ppm).
\end{abstract}

Abstract in English: If accuracy matters, mechanical quantities such as force, torque or pressure are almost exclusively realized by transducers, which are based on strain gauges. To exploit the potential of static measurements the demands for amplifiers with an increased accuracy steadily grow. Unlike transducers, improvement of precision of amplifiers can go very far. Still these highprecision amplifiers can be realised I a very compact size. The new amplifier introduced features two independent (simultaneously measuring) amplifier channels, each of the channels offering an accuracy class of 0.0025 (25 ppm).

Keywords /Mots Clés: - strain gauges, traceability, high-precision amplifiers, accuracy

\section{Introduction}

Nowadays we can see that applying an increased accuracy in a clear trend in industrial applications. Along with the development of electronics and steadily increasing miniaturization more accurate electronic solutions are also more affordable.

If accuracy matters, mechanical quantities such as force, torque or pressure are almost exclusively realized by transducers, which are based on strain gauges. To exploit the potential of static measurements the demands to increase precision of the used amplifiers steadily grow. Unlike transducers, improvement of precision is a big deal, amplifiers can be designed today with highest precision and still can be realised very compact.

This total uncertainty should not be evenly distributed to transducer and amplifier, but the requirement to the amplifier is significantly better, so we put $25 \mathrm{ppm}$ as our goal. One has to remember that the expression - "parts per million" expresses that the permitted deviation of this precision amplifier may only correspond to 25 of a million "parts".

Thus a new amplifier module should feature two independent (simultaneously measuring) amplifier channels, each of the channels offering an accuracy class of 0.0025 (25 ppm). This is realized by using a 24-bit A/D converter for each of the amplifier channels. Both channel of the MX238B are completely synchronous and independent as well as galvanically isolated to each other.
This new module is called Quantum MX 238B belonging to the QuantumX family and referring to the above mentioned famous models with the ending "...38" in their name, such as the predecessor DK38 and the present instrument MGCplus ML38B.

In fact this amplifier is based on a resistive divider and can perform most tasks with sufficient accuracy. For many decades this was not the case. Due to intensive research, HBM can now offer such a dual-channel module at the same time as compact as this is necessary for a realization in the block structure the QuantumX family. It is quite certain, that this a previously unknown compactness will open up new fields of integration into applications. QuantumX now offers the ability to process and display multiple signals of very different accuracybandwidth combinations at the same time. Thus the decisive progress realized with the QuantumX MX238B is, that now the cooperation with all the other measurement modules of the product family QuantumX with PTPv2 identical timing, allows data processing absolutely simultaneously. Thus the isochronous bus system (Firewire) allows synchronous processing with many other physical quantities.

The precision measurement module MX238B thus combines the advantages of combination with all QuantumX members with the possibility of taking measurements with an accuracy class 0.0025 (25 ppm). This is achieved by the use of the carrier frequency principle and an applied carrier frequency of $225 \mathrm{~Hz}$. 


\section{Concept}

To explain the concept in detail I like to repeat some basic topics in strain gauge measurement first.

The resistance of a strain gauge changes under mechanical load. If several strain gauges are combined to a bridge circuit the ratio of the bridge output will change excitation voltage is nearly proportional to the mechanically applied force.

For the electrical measurement of mechanical quantities using strain gauges, it is the ratio of the voltages expressed in $\mathrm{mV} / \mathrm{V}$, which has great importance.

The measured mechanical quantities are captured using transducers and are mapped into the unit $\mathrm{mV} / \mathrm{V}$.

Then we thought about designing the new module quite some conditions have been taken into consideration. Building the module as a mixture of well-known technical principles and applying them in a new way have been used in a better way to achieve an accuracy of $25 \mathrm{ppm}$ what is very good achievement.

For the first time here HBM offers its patented background calibration of this precision class. This ensures that the measurement of the two integrated amplifier can be continued without interruption during the measurement, so even during internal calibration.

The transducer can be recognized with the so-called Transducer Electronic Data Sheet ("TEDS") and the individual properties of the transducer can be stored.

This technology allows to plug in sensors and get started, as a self-recognizing process. The characteristics of a transducer are stored inside as an electronic data sheet. The amplifier can import these data.

The bridge can be supplied by DC. However to supply it by $\mathrm{AC}$ as a "carrier" (frequency fc) may be even the better way. Now we have to distinguish in between the frequency of the carrier and those of the measuring signal.

Precision measurements and this is what we are talking of here, are carried out preferably at $\mathrm{f}_{\mathrm{c}}$ equal $225 \mathrm{~Hz}$ and voltage conditions of $2 \mathrm{mV} / \mathrm{V}$. The frequency of $225 \mathrm{~Hz}$ has been chosen by many National Metrology Institutes (NMI's) around the world, as it is no multiple of the disturbing $50 \mathrm{~Hz}$ or $60 \mathrm{~Hz}$ power supply. It is also implemented into the accredited laboratories in each of these countries.

Another reason is that it keeps the influence of noise low. In figure following figure the spectra of the used carrier frequency principle can be seen. In the graph on the left side the dotted line 6 describes the noise voltage.

At $1 /$ f noise function the choice of $225 \mathrm{~Hz}$ ensures, that one is definitely in the degreased noise, so above the area of significant noise, which occurs close to $0 \mathrm{~Hz}$.

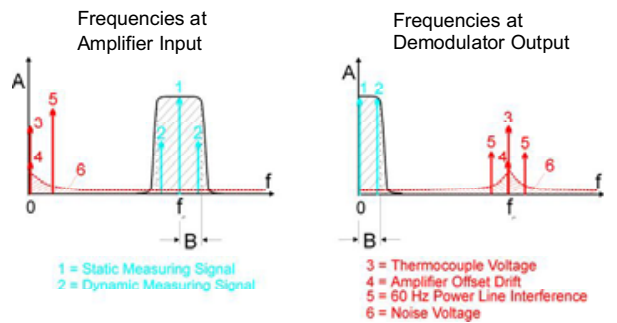

Figure 1: Input and demodulator frequencies in using carrier frequency principle

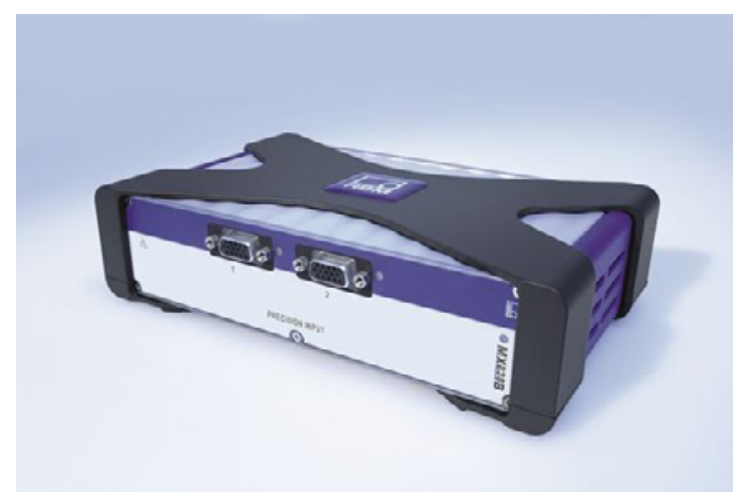

Figure 2: The new amplifier module Quantum MX 238B

It is now posible to combine QuantumX MX238B with all modules of the extensive family of devices QuantumX. This allows a bandwidth suitable for measurement processing of static and quasi-static signals.

MX238B shows its strengths in the cooperation with all measuring modules of the device family QuantumX (fieldbus connection, PTPv2 protocol). In addition to the familiar possibility of combining QuantumX measurement tasks with a wide range of measurement principles, there is now the option to process a wide range of combinations of accuracy and bandwidth.

The below figure shows all the available modules within the Quantum family. As one can see from figure, the individual modules can be stacked on top of each other.

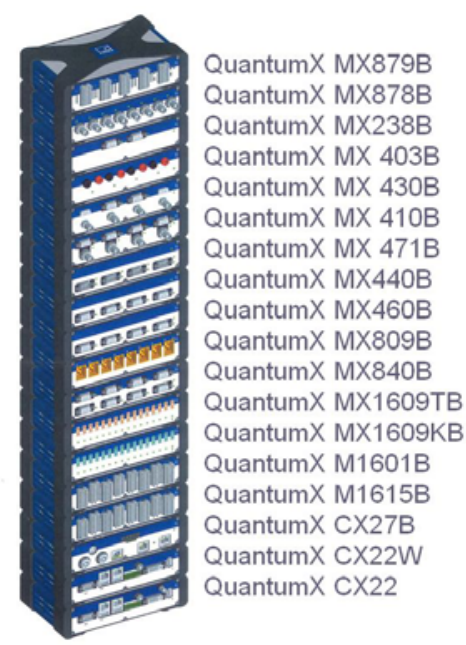

Figure 3: Available modules within the Quantum family 


\section{Results in detail}

The measurement signal is adjusted in the DSP (Digital Signal Processor) in accordance with the auto-calibration values and the selected filter. Therefore it is possible to change the demodulation principal from rectangular to a sinusoidal demodulation. This also reduced the amount of required hardware and space. Because of the ratiometric measurement method the stability of the measurement depends only on the resistance ratio of some precision resistors, small changes are additionally corrected by the auto-calibration cycles (now back-ground-calibration cycles).

Important elements to reach this are internal calibration source the inductive divider is changed to a precision resistive divider with active temperature compensation.

The patented HBM background-calibration ensures uninterrupted measurement, even during the comparison with the internal calibration signal. This method has proven itself in the DMP41 for years. Table 1 shows a comparison of the major analog parameters of the DMP41, the predecessor ML38B and the new QuantumX MX238B.

Still the top series DMP41 offer the best data in long term stability. Since the introduction of the DMP device series $\mathrm{s}$ in 1980 we continuously observed the long-term stability of the measuring chain consisting out of "DMP39 and BN100" (on the basis of inductances we built our own BN100 calibration unit, today called BN100A) and can state that over 37 years its span variation for $+2 \mathrm{mV} / \mathrm{V}$ and $-2 \mathrm{mV} / \mathrm{V}$ signals was every time smaller than the accuracy class of 5 To make such statements for the new QunatumX MX238B will only be possible after some more years.



Fig. 4. Long term stability of the established calibration method of a measuring chain consisting out of BN100 and DMP39

The following table show some main parameters of DMP41, MGCplus ML38B and Quantum MX238B in comparison.

In all shown parameters, the MX238B is significant better than the ML38B. For the highest precision, the DMP41 is still the top of class, performing best in all of the parameters.

\begin{tabular}{|c|c|c|c|}
\hline & DMP41 & ML38B & MX238B \\
\hline $\begin{array}{c}\text { Accuracy Class } \\
\text { (Divider Principal) }\end{array}$ & $\begin{array}{c}5 \mathrm{ppm} \\
\text { (inductiv) } \\
<5 \mathrm{ppm} / 24 \mathrm{~h} \\
\text { Short-Term Drift }\end{array}$ & $\begin{array}{c}25 \mathrm{ppm} \\
\text { (inductiv) }\end{array}$ & $\begin{array}{c}25 \mathrm{ppm} \\
\text { (resistive) }\end{array}$ \\
\hline Long-Term Drift & $\begin{array}{c}<2 \mathrm{ppm} / 24 \mathrm{~h}) \\
<5 \mathrm{ppm} / \mathrm{a} \\
\text { (typ. }<2 \mathrm{ppm} / a)\end{array}$ & $<25 \mathrm{ppm} / 24 \mathrm{~h}$ & $<10 \mathrm{ppm} / 24 \mathrm{~h}$ \\
\hline Zero-Point Drift & $\begin{array}{c}<2 \mathrm{ppm} / 10 \mathrm{~K} \\
\text { (typ. }<1 \mathrm{ppm} / 10 \mathrm{~K})\end{array}$ & $<10 \mathrm{ppm} / 10 \mathrm{~K}$ & $<5 \mathrm{ppm} / 10 \mathrm{~K}$ \\
\hline Gain Drift & $\begin{array}{c}<5 \mathrm{ppm} / 10 \mathrm{~K} \\
(\text { typ. }<2 \mathrm{ppm} / 10 \mathrm{k})\end{array}$ & $<20 \mathrm{ppm} / 10 \mathrm{~K}$ & $<10 \mathrm{ppm} / 10 \mathrm{~K}$ \\
\hline Linearity & $\begin{array}{c}<5 \mathrm{ppm} \\
\text { (typ. }<2 \mathrm{ppm})\end{array}$ & $<20 \mathrm{ppm}$ & $<10 \mathrm{ppm}$ \\
\hline Bandwidth (-3 dB) & \begin{tabular}{c}
$0.04 \ldots 40 \mathrm{~Hz}$ \\
\hline
\end{tabular} & $0.03 \ldots 10 \mathrm{~Hz}$ & $0.01 \ldots 50 \mathrm{~Hz}$ \\
\hline
\end{tabular}

Table1: Some main parameters of DMP41, MGCplus ML38B and Quantum MX238B in comparison.

\section{Advantages in application}

In the introduction it has been expressed, that nowadays applying an increased accuracy is a clear trend in industrial applications. Along with the development of electronics and steadily increasing miniaturization more accurate electronic solutions are also more affordable.

Industrial applications are often based on dynamic measurements, so a change of the quantity to be measured over time. The analysis of these measurements, however, is almost entirely based on static analysis. Here the possibilty to combine QuantumX MX238B with all modules of the extensive family of devices QuantumX comes into play.

A clear advantage in application is the patented background calibration, used for the first time in this precision class. It ensures an uninterrupted measurement, even during the comparison with the internal calibration signal.

\section{Conclusions}

Due to this compact size first time in HBM history a resistive voltage divider had to be used instead of inductive voltage dividers so far. We were able to realize the 25 ppm class .

The measurement results to be presented have been showing a very good time as well as temperature stability of this new, compact amplifier.

We can summarize that generally the market requests more accuracy for measured signals in any application. The question is, whether this higher accuracy is affordable to the user.

HBM therefore has added this new module featuring patented background-calibration and further advantages to the users.

With the new compact full bridge amplifier MX238B a high precision module into the universal DAQ system QuantumX, as a DAQ system solution for all test and measurements tasks has been introduced. 


\section{References}

[1] Hoffmann, K.; “An Introduction to Measurements using Strain Gauges", Hottinger Baldwin Messtechnik GmbH, Darmstadt, Germany, 1989, pp. 145

[2] Kreuzer, M. "High-precision measuring technique for strain gauge transducers" Internal publication of Hottinger Baldwin Mestechnik, GmbH, Darmstadt, Germany, 1999

[3] Kleckers, T., Graef, M. "High capacity reference transducer for tensile forces", IMEKO 22nd TC3, 12th TC5 and 3rd TC22 International Conferences 3 to 5 February, 2014, Cape Town, Republic of South Africa

[4] Kleckers, T, "Precise radial symmetric shear beam force transfer transducer for compression force"; XXI IMEKO World Congress, Sept. 2015, Prague, Czech Republic.

[5] Schäfer, A.; "Force, strain and pressure transducers based on foil type strain gauges", Proceedings of Eurosensors; XXII conference, Dresden, Germany, October 2008

[6] Schäfer, A. "New possibilities with a high pressure measuring chain consisting of reference pressure transducer P3 TopClass BlueLine and DMP 41 high-precision instrument", PTB Report TH6, Brunswick, Germany, April 2016

[7] Haller, M. Viel, W.; Schäfer, A.; "Enhancement of the measurement characteristics of pressure transducers up to 15000 bar through monolithic measuring design and foil type strain gauges", Proceedings of XIX IMEKO World Congress Lisbon, Portugal, 2009

[8] Schäfer, A.; et al.; "A new type of transducer for accurate and dynamic pressure measurement up to 15000 bar using foil type strain gauges", XVII IMEKO World Congress 2003, Dubrovnik, Croatia, 2003

[9] Eichstädt. S., Esward, T. J., Schäfer, A. "On the necessity of dynamic calibration for improved traceability of mechanical quantities" XXI IMEKO World Congress, Sept. 2015, Prague, Czech Republic.

[10] Schäfer, A.; "Dynamic measurements as an emerging field in dynamic metrology"; PTBMitteilungen 125(2015) Volume 2

[11] IEEE 1451.4 Standard for Smart Transducers Secretary, issued by IEEE 1451.4 Standard Working Group, 1451.2WG, 2004

[12] Schäfer, A. "Challenges in dynamic torque and force measurement with special regard to industrial demands", BIPM Workshop on Challenges in Dynamic Measurements

[13] Schäfer, A. "Development results for static and dynamic torque measurement", Proceedings of torque symposium of "Zentrum für Kon- struktionswerkstoffe“, MPA (State Material Testing Institute), Darmstadt, Germany, 2014

[14] Schäck, M. "Underestimated impact of measuring cables on high-precision carrier frequency amplifier results and compensation methods therefor" XXI IMEKO World Congress, Sept. 2015, Prague, Czech Republic.

[15] Schäfer, A.; Kitzing, H.; "DMP41- a new chapter of ultra-precision instrument for strain gauge transducers", XX IMEKO World Congress, September 2012, Busan, Republic of Korea

[16] Schäfer, A.; "The ultra-precision instrument DMP41-first experience \& appropriate filter settings", IMEKO 22nd TC3, 12th TC5 and 3rd TC22 International Conferences, February, 2014, Cape Town, Republic of South Africa

[17] Schäck, M.; "High-precision measurement of strain gauge transducers at the physical limit without any calibration interruptions" IMEKO 22nd TC3, 12th TC5 and 3rd TC22 International Conferences, February, 2014, Cape Town, Republic of South Africa

[18] Vollmert, R. ; Ramm, G. "Realization, maintenance and dissemination of the measurand $>>A C$ voltage ratio in $m V / V<<$ for strain gauge measurements", Proceedings of the 17th International Conference of IMEKO TC3, Istanbul, Turkey, 17-21, September, 2001

[19] Ramm, G. “ Investigation of bridge standards for use in strain-gauge measurements" Reports in Applied Measurement RAM, Vol. 6 (1990), No. 1, pp. 26-30

[20] Ramm, G.; Peters, M. "Investigation of the Calibration Signal of Force Measuring Devices". IMEKO Force and Mass 1986, Amsterdam, Conference Digest, ISBN 90-247-3351-0, pp. 267-273

[21] Ramm, G. „Untersuchung des Fehlverhaltens eines Brückennormals vom Typ BN 100“ PTB Report PTB-E-30, ISBN 3-88314-655-2, April 1978

[22] Crößmann , F. "Investigation of the calibration capabilities of a $1 \mathrm{kN} \cdot \mathrm{m}$ reference calibration machine", IMEKO TC3/ TC5/TC22 in Helsinki, Finland, May 2017

[23] Kleckers, T. "New reference load cells for tension and compression with capacities of more than 1 MN", IMEKO TC3/ TC5/TC22 in Helsinki, Finland, May 2017

[24] Schäck, M. "Long term proven and optimized high-precision $225 \mathrm{~Hz}$ CF technology in a universal DAQ", IMEKO TC3/ TC5/TC22 in Helsinki, Finland, May 2017

[25] Schäfer, A. "Evaluation of dynamic measurement uncertainty for industrial applications" IMEKO TC3/ TC5/TC22 in Helsinki, Finland, May 2017 